\title{
Aggregate of Alkoxy-Bridged Re(I)-Rectangles as a Probe for Photoluminescence Quenching
}

\author{
P. Thanasekaran, ${ }^{\dagger}$ Jing-Yun Wu, ${ }^{\dagger}$ Bala. Manimaran ${ }^{\dagger}$ T. Rajendran, ${ }^{\dagger}$ I-Jy Chang,, \\ S. Rajagopal, ${ }^{\dagger, \mathbb{I}}$ Gene-Hsiang Lee, ${ }^{\S}$ Shie-Ming Peng, ${ }^{\S}$ and Kuang-Lieh Lu, ${ }^{*}$, \\ Institute of Chemistry, Academia Sinica, Taipei 115, Taiwan, Department of Chemistry, National Taiwan \\ Normal University, Taipei 117, Taiwan, Department of Chemistry, National Taiwan University, Taipei 107, \\ Taiwan, and School of Chemistry, Madurai Kamaraj University, Madurai, 625 021, India
}

Received: May 31, 2007; In Final Form: July 30, 2007

\begin{abstract}
Alkoxy-bridged rhenium(I) rectangles $\left[\left\{(\mathrm{CO})_{3} \operatorname{Re}(\mu \text {-OR })_{2} \operatorname{Re}(\mathrm{CO})_{3}\right\}_{2}(\mu \text {-bpy })_{2}\right]\left(\mathbf{1}, \mathrm{R}=\mathrm{C}_{4} \mathrm{H}_{9} ; \mathbf{2}, \mathrm{R}=\mathrm{C}_{8} \mathrm{H}_{17} ; \mathbf{3}\right.$, $\mathrm{R}=\mathrm{C}_{12} \mathrm{H}_{25}$; bpy $=4,4^{\prime}$-bipyridine) comprising long alkyl chains form optically transparent aggregates and exhibit luminescence enhancement in the presence of water. The aggregation of $\operatorname{Re}(\mathrm{I})$-rectangle was followed using a light-scattering technique. Presumably, the enhanced luminescence efficiency resulted from restriction of torsional molecular motion in the aggregates. In addition, the rate of bimolecular quenching of $\operatorname{Re}(\mathrm{I})$ aggregates in the triplet excited state by various electron donors (amines) and acceptors (quinones) was efficient. These results indicate that the excited state of aggregated $\operatorname{Re}(\mathrm{I})$ surfactants with an electron acceptor and donor facilitate the electron-transfer quenching process after they became preassociated inside the $\operatorname{Re}(\mathrm{I})$ aggregated species. These synthesized compounds may be useful fluorescent materials in optoelectronic applications.
\end{abstract}

\section{Introduction}

Photophysical methods employing luminescent probes are commonly used to study self-assembly of amphiphilic molecules in solution. ${ }^{1}$ Micelles and reverse micelles are supramolecular aggregates that change the photophysical and photochemical behavior of probe molecules. ${ }^{1-4}$ These aggregates promote inclusion or exclusion of compounds in the micelle core or at the micelle interface on the basis of hydrophobic and electrostatic interactions. ${ }^{2 a, 5}$ At the same time, aggregation affects, sometimes drastically, the luminescence of the molecule, thus leading to interesting photophysical properties. ${ }^{6}$ Recently, it was reported that some porphyrin amphiphiles self-organize in aqueous media to form supramolecular assemblies. ${ }^{7}$ The highly ordered porphyrin arrays act as redox centers for light energy conversion and as oxygen binding sites for $\mathrm{O}_{2}$ transport. $\mathrm{Ru}-$ (II)-based metallosurfactants, forming inverted aggregates, also have been reported. ${ }^{8}$ Furthermore, several calixarenes bearing long aliphatic chains form vesicles or micelles that can bind guest aromatic molecules. ${ }^{9}$

Electron transfer is an active topic in chemical research, ${ }^{10}$ particularly in solar energy conversion and photosynthetic processes. It is well-known that medium effects, such as solvent polarity, heterogeneity of the microenvironment, and the addition of salts, have an important influence on the dynamics of photoinduced electron transfer between donor and acceptor in solution. ${ }^{2 a, 11} \operatorname{Re}(\mathrm{I})$-containing cyclophanes have been synthesized for their interesting photophysical and photochemical properties. ${ }^{12-16}$ A variety of substances act to quench $\operatorname{Re}(\mathrm{I})$ complexes in the excited state by participating in electron or energy transfer reactions. ${ }^{17,18}$ Although quenching of several

* To whom correspondence should be addressed. Fax: +886-2 27831237. E-mail: lu@chem.sinica.edu.tw.

$\dagger$ Academia Sinica.

$\doteqdot$ National Taiwan Normal University.

$\S$ National Taiwan University.

II Madurai Kamaraj University.
$\operatorname{Re}(\mathrm{I})$ complexes in micellar solutions were tested, ${ }^{19}$ no emission quenching in surfactant $\operatorname{Re}(\mathrm{I})$ complexes, particularly, in nanometer-sized supramolecular systems, has been reported, except in our preliminary communication. ${ }^{20}$ Herein we report on the $\mathrm{ON}-\mathrm{OFF}$ phenomenon of aggregation-induced emission (AIE) enhancement in $\operatorname{Re}(\mathrm{I})$ molecular rectangles and aggregationfacilitated electron transfer between the rectangular compounds and electron donors and acceptors.

\section{Experimental Section}

2.1. Chemicals and Instrumentation. Reagents were used as received. Acetonitrile used in this study was of spectroscopic grade, and deionized water was used throughout the experiment. Prior to use, the solvents were checked for spurious emissions in the region of interest and found to be satisfactory. ${ }^{1} \mathrm{H}$ and ${ }^{13} \mathrm{C}$ NMR spectra were measured on Bruker AC 300 and AMX400 FT-NMR spectrometers. IR spectra were taken on a PerkinElmer 882 FT-IR spectrometer. Elemental analyses were performed using a Perkin-Elmer $2400 \mathrm{CHN}$ elemental analyzer. Electronic absorption spectra were recorded on a HewlettPackard 8453 spectrophotometer. Steady-state emission spectra were obtained in oxygenated aqueous acetonitrile solution at ambient temperature with a Hitachi F4500 fluorescence spectrophotometer. Both excitation and emission band passes used were $5.0 \mathrm{~nm}$. Emission quantum yields, $\Phi_{\mathrm{em}}$, were calculated by the relative method, based on the comparison of the areas of the fluorescence spectra of a reference and of the sample. Excited-state lifetimes of $\mathbf{3}$ in acetonitrile and acetonitrile-water mixtures were measured by a home constructed time-resolved laser spectrometer. The instrument was equipped with a Quanta Ray GCR-170, pulsed Nd:YAG laser. The third harmonic of the laser $(355 \mathrm{~nm}$, fwhm $=10 \mathrm{~ns})$ was used as the excitation source. Emission signals were focused into an ARC SpectraPro500 double monochromator. The monochromator output was sent into a photomultiplier tube (PMT) (Hamamatsu, R928), and the signal was digitized by a LeCory 9350A digitizer. 
Single-exponential decays were observed in each case, and the lifetimes obtained were found to be reproducible within $\pm 5 \%$. Decay traces were transferred to a personal computer loaded with the commercial software Origin 4.0.

2.2. Synthesis of $\left[\left\{(\mathrm{CO})_{3} \operatorname{Re}(\mu-\mathrm{OR})_{2} \operatorname{Re}(\mathrm{CO})_{3}\right\}_{2}(\mu \text {-bpy })_{2}\right](1$, $\left.\mathbf{R}=\mathbf{C}_{4} \mathbf{H}_{9} ; 2, \mathbf{R}=\mathbf{C}_{8} \mathbf{H}_{17} ; 3, \mathbf{R}=\mathbf{C}_{12} \mathbf{H}_{25}\right)$. A suspension containing a mixture of $\operatorname{Re}_{2}(\mathrm{CO})_{10}(1.0 \mathrm{mmol})$ and $4,4^{\prime}$ bipyridine (bpy, $1.0 \mathrm{mmol}$ ) in $100 \mathrm{~mL}$ of aliphatic alcohol (1butanol for 1, 1-octanol for 2, and 1-dodecanol for 3) was refluxed for $24 \mathrm{~h}$ and then cooled to $25{ }^{\circ} \mathrm{C}$. The crystals were separated by filtration, the solvent from the filtrate was removed by vacuum, and the residue was redissolved in a minimum quantity of $\mathrm{CH}_{2} \mathrm{Cl}_{2}$ and passed through a short silica gel column to get the pure product.

1. Yield: $84 \%$ (0.42 mmol). IR $\left(\mathrm{CH}_{2} \mathrm{Cl}_{2}, \mathrm{~cm}^{-1}\right): v_{\mathrm{CO}} 2022$ s, $2010 \mathrm{~m}, 1912 \mathrm{~m}, 1890 \mathrm{vs} .{ }^{1} \mathrm{H}$ NMR $\left(300 \mathrm{MHz}\right.$, acetone- $d_{6}$, ppm): $\delta 8.65\left(\mathrm{~d},{ }^{3} J=6.6 \mathrm{~Hz}, 8 \mathrm{H}, \mathrm{H}^{3}\right), 7.84\left(\mathrm{~d},{ }^{3} J=6.6 \mathrm{~Hz}\right.$, $\left.8 \mathrm{H}, \mathrm{H}^{2}\right), 4.45(\mathrm{~m}, 8 \mathrm{H}), 2.17(\mathrm{~m}, 8 \mathrm{H}), 1.51(\mathrm{~m}, 8 \mathrm{H}), 1.10(\mathrm{t}$, $\left.{ }^{3} J=7.4 \mathrm{~Hz}, 12 \mathrm{H}\right) \cdot{ }^{13} \mathrm{C}$ NMR $\left(75 \mathrm{MHz}\right.$, acetone- $\left.d_{6}, \mathrm{ppm}\right): \delta$ 198.9, $198.4(1: 2, \mathrm{CO}), 153.6\left(\mathrm{C}^{3}\right), 146.2\left(\mathrm{C}^{1}\right), 124.2\left(\mathrm{C}^{2}\right), 82.7$ $\left(\mathrm{CH}_{2}\right), 36.7\left(\mathrm{CH}_{2}\right), 19.2\left(\mathrm{CH}_{2}\right), 14.6\left(\mathrm{CH}_{3}\right) . \mathrm{UV}-\mathrm{vis}\left(\mathrm{CH}_{3} \mathrm{CN}\right.$, $\mathrm{nm}): \lambda_{\max } 384$ (MLCT), 249 (LIG). Emission (nm): $\lambda_{\max } 666$. Anal. Calcd for $\mathrm{C}_{48} \mathrm{H}_{52} \mathrm{~N}_{4} \mathrm{O}_{16} \mathrm{Re}_{4}$ : C, 34.20; H, 3.11; N, 3.32. Found: C, 34.20; H, 3.02; N, 3.36. Mass (FAB, $\left.{ }^{187} \mathrm{Re}\right): \mathrm{m} / \mathrm{z}$ $1688\left(\mathrm{M}^{+}\right)$.

2. Yield: $86 \%(0.43 \mathrm{mmol}) . \mathrm{IR}\left(\mathrm{CH}_{2} \mathrm{Cl}_{2}, \mathrm{~cm}^{-1}\right): v_{\mathrm{CO}} 2022$ s, $2009 \mathrm{~m}, 1912 \mathrm{~m}, 1890 \mathrm{vs} .{ }^{1} \mathrm{H}$ NMR $\left(300 \mathrm{MHz}\right.$, acetone- $d_{6}$, ppm): $\delta 8.65\left(\mathrm{~d},{ }^{3} J=6.7 \mathrm{~Hz}, 8 \mathrm{H}, \mathrm{H}^{3}\right), 7.83\left(\mathrm{~d},{ }^{3} J=6.7 \mathrm{~Hz}\right.$, $\left.8 \mathrm{H}, \mathrm{H}^{2}\right), 4.44(\mathrm{~m}, 8 \mathrm{H}), 2.20(\mathrm{~m}, 8 \mathrm{H}), 1.49(\mathrm{~m}, 24 \mathrm{H}), 1.35$ $(\mathrm{m}, 16 \mathrm{H}), 0.92\left(\mathrm{t},{ }^{3} \mathrm{~J}=6.9 \mathrm{~Hz}, 12 \mathrm{H}\right) .{ }^{13} \mathrm{C} \mathrm{NMR}(75 \mathrm{MHz}$, acetone- $\left.d_{6}, \mathrm{ppm}\right): \delta 198.8,198.3(1: 2, \mathrm{CO}), 153.5\left(\mathrm{C}^{3}\right), 146.1$ $\left(\mathrm{C}^{1}\right), 124.1\left(\mathrm{C}^{2}\right), 82.8\left(\mathrm{CH}_{2}\right), 34.4\left(\mathrm{CH}_{2}\right), 32.5\left(2 \mathrm{CH}_{2}\right), 30.3$ $\left(\mathrm{CH}_{2}\right), 25.8\left(\mathrm{CH}_{2}\right), 23.3\left(\mathrm{CH}_{2}\right), 14.5\left(\mathrm{CH}_{3}\right) . \mathrm{UV}-\mathrm{vis}\left(\mathrm{CH}_{3} \mathrm{CN}\right.$, $\mathrm{nm}): \lambda_{\max } 398$ (MLCT), 248 (LIG). Emission (nm): $\lambda_{\max } 666$. Anal. Calcd for $\mathrm{C}_{64} \mathrm{H}_{84} \mathrm{~N}_{4} \mathrm{O}_{16} \mathrm{Re}_{4} \cdot\left(\mathrm{C}_{8} \mathrm{H}_{18} \mathrm{O}\right)$ : C, 42.38; H, 5.04; $\mathrm{N}, 2.74$. Found: $\mathrm{C}, 42.18 ; \mathrm{H}, 5.12 ; \mathrm{N}, 2.34$. Mass (FAB, $\left.{ }^{187} \mathrm{Re}\right): \mathrm{m} / \mathrm{z} 1912\left(\mathrm{M}^{+}\right)$.

3. Yield: $87 \%$ (0.44 mmol). IR $\left(\mathrm{CH}_{2} \mathrm{Cl}_{2}, \mathrm{~cm}^{-1}\right)$ : $v_{\mathrm{CO}} 2022$ s, $2010 \mathrm{~m}, 1912 \mathrm{~m}, 1890 \mathrm{vs} .{ }^{1} \mathrm{H}$ NMR $\left(300 \mathrm{MHz}\right.$, acetone- $d_{6}$, ppm): $\delta 8.63\left(\mathrm{~d},{ }^{3} J=6.5 \mathrm{~Hz}, 8 \mathrm{H}, \mathrm{H}^{3}\right), 7.80\left(\mathrm{~d},{ }^{3} \mathrm{~J}=6.5 \mathrm{~Hz}\right.$, $\left.8 \mathrm{H}, \mathrm{H}^{2}\right), 4.43(\mathrm{~m}, 8 \mathrm{H}), 2.19(\mathrm{~m}, 8 \mathrm{H}), 1.48(\mathrm{~m}, 24 \mathrm{H}), 1.30$ $(\mathrm{m}, 48 \mathrm{H}), 0.89\left(\mathrm{t},{ }^{3} \mathrm{~J}=6.5 \mathrm{~Hz}, 12 \mathrm{H}\right) .{ }^{13} \mathrm{C} \mathrm{NMR}(75 \mathrm{MHz}$, acetone- $\left.d_{6}, \mathrm{ppm}\right): \delta 199.0,198.3(1: 2, \mathrm{CO}), 153.5\left(\mathrm{C}^{3}\right), 146.0$ $\left(\mathrm{C}^{1}\right), 124.0\left(\mathrm{C}^{3}\right), 82.9\left(\mathrm{CH}_{2}\right), 34.3\left(\mathrm{CH}_{2}\right), 32.6\left(\mathrm{CH}_{2}\right), 30.3(3$ $\left.\mathrm{CH}_{2}\right), 30.0\left(2 \mathrm{CH}_{2}\right), 25.8\left(2 \mathrm{CH}_{2}\right), 23.3\left(\mathrm{CH}_{2}\right), 14.4\left(\mathrm{CH}_{3}\right) . \mathrm{UV}-$ vis $\left(\mathrm{CH}_{3} \mathrm{CN}, \mathrm{nm}\right)$ : $\lambda_{\max } 382$ (MLCT), 247 (LIG). Emission (nm): $\lambda_{\max }$ 666. Anal. Calcd for $\mathrm{C}_{80} \mathrm{H}_{116} \mathrm{~N}_{4} \mathrm{O}_{16} \mathrm{Re}_{4}$ : C, 45.01; H, 5.48; N, 2.62. Found: C, 45.41; H, 5.61; N, 2.69. Mass (FAB, $\left.{ }^{187} \mathrm{Re}\right): m / z 2136\left(\mathrm{M}^{+}\right)$.

2.3. Laser Light-Scattering. Measurements of light-scattering intensity were performed at $20{ }^{\circ} \mathrm{C}$ over the angular range of $20-150^{\circ}$ with a DLS-7000 light-scattering photometer (Photal Otsuka Electronics, Japan), equipped with an LS-71 control unit using a $10 \mathrm{~mW} \mathrm{He}-\mathrm{Ne}$ laser emitting vertically polarized light at a wavelength of $\lambda=632.8 \mathrm{~nm}$. The sample cell was mounted at the center of a temperature-controlled, refractive index matched bath. Intensity measurements were calibrated against toluene (Rayleigh ratio: $1.4 \times 10^{-5} \mathrm{~cm}^{-1}$ ). ${ }^{21}$ The nanoaggregate mixtures were freshly prepared by adding a poor solvent (water) into acetonitrile solutions of $\mathbf{3}$ with vigorous shaking. For example, a nanoparticle mixture of $\mathbf{3}$ was prepared by adding $5 \mathrm{~mL}$ of water to $5 \mathrm{~mL}$ of an acetonitrile solution of $\mathbf{3}$ in a $10 \mathrm{~mL}$ sintered metal fibers (SMF). The concentrations of all nanoaggregate mixtures were adjusted to $10^{-6} \mathrm{M}$.

Static light-scattering (SLS) measurements were carried out using the Zimm method ${ }^{22}$ to obtain $R_{\mathrm{g}}, M_{\mathrm{w}}$, and $A_{2}$ values. The Zimm method is based on eq 1

$$
\frac{K c}{R_{\theta}}=\frac{1+16 \pi^{2} n_{0}^{2} R_{\mathrm{g}}^{2}}{3 \lambda^{2}} \sin ^{2}\left(\frac{\theta}{2}\right)\left(\frac{1}{M_{\mathrm{w}}}+2 A_{2}\right)
$$

where $c$ is the weight concentration, $R_{\theta}$ is the Rayleigh ratio (a parameter proportional to the scattering intensity, obtained by SLS for each $c$ and $\theta$ value), $n_{0}$ is the refractive index of the solvent, and $K$ is defined by eq 2

$$
K=\frac{4 \pi^{2} n_{0}^{2}\left(\frac{\mathrm{d} n}{\mathrm{~d} c}\right)^{2}}{N_{\mathrm{A}} \lambda^{4}}
$$

Here, $\mathrm{d} n / \mathrm{d} c$ is the specific refractive index increment of the solution, $N_{\mathrm{A}}$ is Avogadro's number, and $\lambda$ is the wavelength of the laser. Extrapolation of the angular and concentration measurements to zero gives the values of $A_{2}, R_{\mathrm{g}}$, and $M_{\mathrm{w}}$. The measurements in this study were carried out at scattering angles ranging from $20^{\circ}$ to $150^{\circ}$ with an interval of $10^{\circ}$. The experimental determination of $\mathrm{d} n / \mathrm{d} c$, was hampered by the need for a considerably higher concentration of $\mathbf{3}$ in $50 \%$ aqueous acetonitrile mixtures. The refractive index increment $(\mathrm{d} n / \mathrm{d} c)$ of molecular aggregation of this system was determined using a double-beam differential refractometer, model DRM-1021 (Photal Otsuka Electronics, Japan).

Dynamic light-scattering (DLS) measures intensity fluctuations over time and relates these fluctuations to the properties of the scattering objects. The frequency of scattered light fluctuates around the incident light due to constant motion of the polymer molecules. In general, dynamic variables always are used to describe the response of the scattering molecules to the incident light. From eq 3

$$
\Gamma=D q^{2}
$$

the translational diffusion coefficient, $D$, can be determined. $\Gamma$ is the decay rate, which is the inverse of the relaxation time, $\tau$; $q$ is the scattering vector, defined by eq 4

$$
q=\frac{4 \pi n \sin \left(\frac{\theta}{2}\right)}{\lambda}
$$

where $\theta$ is the scattering angle, $n$ is the refractive index of the solution, and $\lambda$ is the wavelength of the incident light. DLS was conducted at a scattering angle of $90^{\circ}$ using both cumulant and histogram software. The diffusion coefficient was deduced using standard second-order cumulant analysis of the autocorrelation function measured at a $90^{\circ}$ angle. From the apparent diffusion coefficient, the hydrodynamic radius, $R_{\mathrm{H}}$, of the micelles was calculated using the Stokes-Einstein eq 5

$$
R_{\mathrm{H}}=\frac{k_{\mathrm{B}} T}{6 \pi \eta D}
$$

where $k_{\mathrm{B}}$ is the Boltzmann constant, $T$ is the absolute temperature, $D$ is the diffusion constant, and $\eta$ is the viscosity of the solvent. All solutions were filtered with a $0.20 \mu \mathrm{m}$ syringe filter before measurement. The reproducibility of the DLS results was 


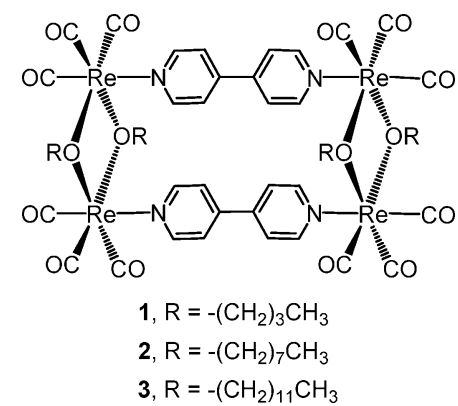

Figure 1. Structures of alkoxy-bridged rhenium(I) molecular rectangles 1-3.

checked by analyzing each sample at least 10 times. The standard deviation between these independent measurements was less than $2 \%$.

2.4. Crystallographic Determination. A suitable single crystal of 1 with dimensions of $0.20 \times 0.20 \times 0.20 \mathrm{~mm}^{3}$ was selected for indexing and the collection of intensity data. Measurements were performed at 295(2) K within the limits of $1.73^{\circ}<\theta<25.00^{\circ}$ using a NONIUS CAD4 diffractometer equipped with graphite-monochromatized Mo $\mathrm{K} \alpha$ radiation $(\lambda$ $=0.71073 \AA$ ). An empirical absorption correction based on the psi-scan method was applied $\left(T_{\min / \max }=0.1887 / 0.2648\right)$. The structure was solved by direct methods and refined by full-matrix least-squares method on $F^{2}$ values using the SHELX-9723 program packages. $\mathrm{C}_{48} \mathrm{H}_{52} \mathrm{~N}_{4} \mathrm{O}_{16} \mathrm{Re}_{4}, M_{\mathrm{r}}=1685.74$, monoclinic, $P 2{ }_{1} / n, a=9.2803(19) \AA, b=18.613(2) \AA, c=15.189(2) \AA$, $\beta=93.90(2)^{\circ}, V=2617.6(7) \AA^{3}, Z=2, \rho_{\text {calcd }}=2.139 \mathrm{~g} \mathrm{~cm}^{-3}$, $F_{000}=1592, \mu=9.290 \mathrm{~mm}^{-1}(\lambda=0.71073 \AA)$. Final $R$ indices of $R_{1}=0.0307$ and $w R_{2}=0.0712$ for 3162 reflections $(I>$ $2 \sigma(I)$ ), and $R_{1}=0.0627$ and $w R_{2}=0.0786$ for all data (4602) and 330 parameters. GOF $=1.036$. One of the carbon atoms belonging to the butoxy chain in the asymmetric unit is disordered over two positions with the site-occupation factor (S.O.F.) of 0.7 and 0.3 for $\mathrm{C} 22$ and $\mathrm{C}_{22}$, respectively. Anisotropical thermal factors were assigned to non-hydrogen atoms, except $\mathrm{C} 22^{\prime}$. The positions of hydrogen atoms were generated geometrically and assigned isotropic thermal parameters.

\section{Results and Discussion}

When $\operatorname{Re}_{2}(\mathrm{CO})_{10}$ was treated with 4,4'-bipyridine (bpy) in the presence of aliphatic alcohols (i.e., 1-butanol, 1-octanol, and 1-dodecanol) under refluxing conditions, alkoxy-bridged molecular rectangles $\left[\left\{(\mathrm{CO})_{3} \operatorname{Re}(\mu \text {-OR })_{2} \operatorname{Re}(\mathrm{CO})_{3}\right\}_{2}(\mu \text {-bpy })_{2}\right](\mathbf{1}, \mathrm{R}$ $=\mathrm{C}_{4} \mathrm{H}_{9} ; 2, \mathrm{R}=\mathrm{C}_{8} \mathrm{H}_{17} ; 3, \mathrm{R}=\mathrm{C}_{12} \mathrm{H}_{25}$ ) were obtained in high yields (Figure 1). Synthetic routes to these compounds containing long alkyl chains, $\mathbf{1}-\mathbf{3}$, have been communicated previously. ${ }^{20}$ Spectroscopic characterizations of $\mathbf{1}-\mathbf{3}$ by ${ }^{1} \mathrm{H}$ and ${ }^{13} \mathrm{C}$ NMR spectra, IR spectra, FAB-MS data, and microanalyses were in agreement with the rectangular structures. The structure of 1 was further examined by single-crystal X-ray diffraction analysis. The IR spectra of $\mathbf{1 - 3}$ exhibited identical CO stretching patterns and were similar to previous reports. ${ }^{13,14}$ Rectangles $\mathbf{1}-\mathbf{3}$ containing long alkyl chains were not soluble in water but were soluble in organic solvents. The solubility could be tuned by increasing the length of the alkoxy groups present in the rectangle.

3.1. Crystal Structure. Results of the X-ray crystallography revealed that 1 adopts an $\mathrm{M}_{4} \mathrm{~L}_{4} \mathrm{~L}_{2}^{\prime}$ metallorectangle: four fac$\operatorname{Re}(\mathrm{CO})_{3}$ corners, four butoxy bridges, and two bpy ligands (Figure 2). The bond lengths of $\mathrm{Re}-\mathrm{C}(1.878(10)-1.916(9) \AA)$, $\mathrm{Re}-\mathrm{O}(2.139(5)-2.148(5) \AA)$, and $\mathrm{Re}-\mathrm{N}(2.218(6)-2.227(6)$

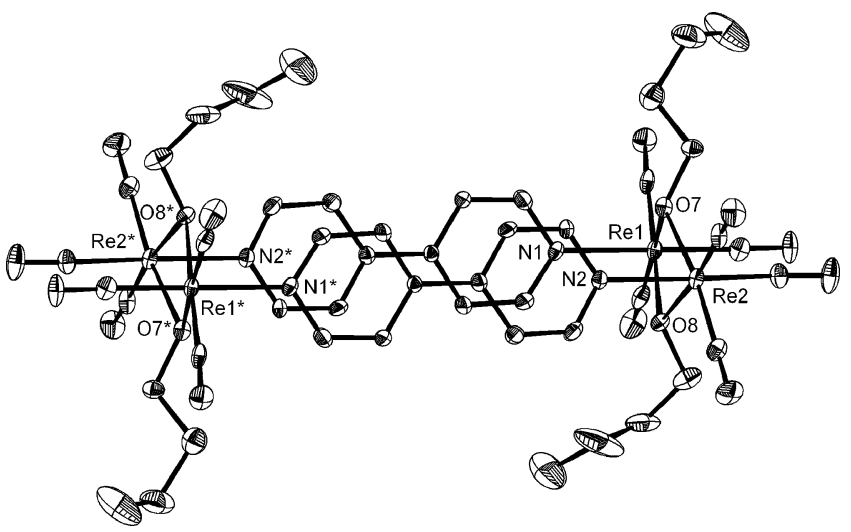

Figure 2. ORTEP plot of 1. Hydrogen atoms and disordered butoxy carbon atoms have been omitted for clarity. The thermal ellipsoids represent $30 \%$ occupancy. Selected bond lengths $[\AA]$ : Re1-C1, 1.878(10); Re1-C2, 1.895(10); Re1-C3, 1.912(10); Re1-O7, 2.141(5); Re1-O8, 2.139(5); Re1-N1, 2.218(6); Re2-C4, 1.896(9); Re2-C5, 1.890(10); Re2-C6, 1.916(9); Re2-O7, 2.141(5); Re2-O8, 2.148(5); $\operatorname{Re} 2-\mathrm{N} 2,2.227(6)$.

$\AA$ ) are normal. The rhenium atoms define a rectangle $11.52 \AA$ long and $3.38 \AA$ wide. The bipyridines approach within 3.73 $\AA$, exhibiting weak face-to-face $\pi-\pi$ interactions. The coordinated planar bipyridine ligands are perpendicular to the rectangular plane defined by the rhenium atoms, whereas each butoxy group is bridged to two rhenium atoms with $\mathrm{Re}-\mathrm{O}-$ Re bond angles of $104.3(2)-104.5(2)^{\circ}$. The cavity in rectangle $\mathbf{1}$ is not large enough to accommodate a guest molecule.

3.2. Optical Properties. The absorption spectrum of $\mathbf{3}$ in acetonitrile $\left(\mathrm{CH}_{3} \mathrm{CN}\right)$ showed an intense band at $241 \mathrm{~nm}$ with a shoulder at $266 \mathrm{~nm}$, corresponding to the ligand-centered (LC) transition, and a broad band at $385 \mathrm{~nm}$, which was attributed to the metal-to-ligand charge transfer (MLCT) transition. Addition of water into the $\mathrm{CH}_{3} \mathrm{CN}$ solution of $\mathbf{3}\left(6 \times 10^{-6} \mathrm{M}\right)$ changed the absorption spectrum (Supporting Information Figure S1). In $10 \%$ water content, the intensity of the LC band at $241 \mathrm{~nm}$ was reduced, while the shoulder at $266 \mathrm{~nm}$ became more pronounced. When the water content was increased from $20 \%$ to $90 \%$, the bands at 241 and $266 \mathrm{~nm}$ shifted to 248 and 272 $\mathrm{nm}$, respectively, with concomitant increases in band intensity. On the other hand, the MLCT band shifted from 385 to 390 $\mathrm{nm}$ after the addition of water. The slight red-shift in the UVvis spectrum can be explained by the decrease in stacking efficiency which resulted from the increase in the length of side chains. ${ }^{24}$ Furthermore, the absorption spectra suggest a scattered light pattern with an exponential frequency function that tails down at $600 \mathrm{~nm}$. These results strongly imply the existence of nanoparticle suspensions. ${ }^{25}$ Molecular aggregation seems to be the best explanation for these spectral changes. It has been reported that silole molecules aggregate when a poor solvent (water) is added to the acetone solution. ${ }^{26}$

3.3. Photophysical Properties. The dilute acetonitrile solutions of $\mathbf{1}-\mathbf{3}$ showed weak emission. Since the solubility of $\mathbf{3}$ in acetonitrile was better than that of $\mathbf{1}$ or $\mathbf{2}$, compound $\mathbf{3}$ was selected for further study of emission behavior. Surprisingly, when a large amount (90\%) of water was added to the acetonitrile solution of $\mathbf{3}$ (with the final concentration of the mixture being adjusted to $6 \times 10^{-6} \mathrm{M}$ ), an intense photoluminescence (PL) spectrum was recorded under the same measurement conditions. Addition of water dramatically enhanced the emission intensity of rectangle $\mathbf{3}$, as shown in Figure 3. The effect was moderate for rectangles $\mathbf{1}$ and 2. Although the MLCT absorption band of $\mathbf{3}$ was red-shifted by only $5 \mathrm{~nm}$, increasing the water volume fraction in acetonitrile-water mixtures 


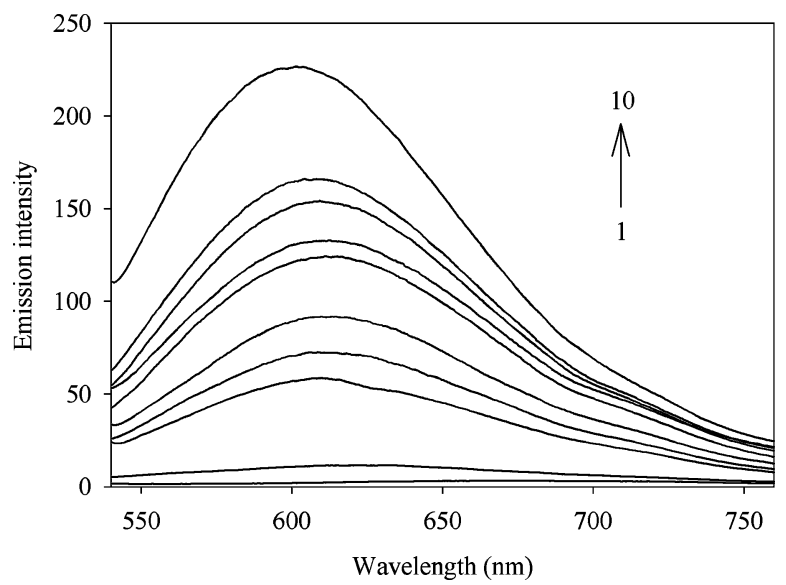

Figure 3. Aggregation-induced emission (AIE) enhancement of $\mathbf{3}$ in acetonitrile upon increasing water content: (1) $0 \%$, (2) $10 \%$, (3) $20 \%$, (4) $30 \%,(5) 40 \%$, (6) $50 \%$, (7) $60 \%$, (8) $70 \%$, (9) $80 \%$, and (10) $90 \%$. The excitation wavelength was $390 \mathrm{~nm}$.

TABLE 1: Wavelength of Emission Maximum $\left(\lambda_{\max }{ }^{\mathrm{em}}\right)$, Emission Quantum Yield $\left(\Phi_{\mathrm{em}}\right)$, and Lifetime $(\tau)$ of Rectangle 3 in Various Acetonitrile-Water (v/v) Mixtures

\begin{tabular}{rccccc}
\hline & \multicolumn{3}{c}{ solvent composition } & & \\
\cline { 2 - 3 } no. & $\mathrm{MeCN}(\%)$ & $\mathrm{H}_{2} \mathrm{O}(\%)$ & $\lambda_{\max }{ }^{\mathrm{em}}(\mathrm{nm})^{a}$ & $\Phi_{\mathrm{em}}\left(\times 10^{-3}\right)^{b}$ & $\tau(\mathrm{ns})$ \\
\hline 1 & 100 & 00 & 666 & 0.39 & 11 \\
2 & 90 & 10 & 634 & 0.46 & 13 \\
3 & 80 & 20 & 612 & 1.64 & 120 \\
4 & 70 & 30 & 611 & 1.73 & 124 \\
5 & 60 & 40 & 613 & 2.06 & 135 \\
6 & 50 & 50 & 613 & 2.37 & 137 \\
7 & 40 & 60 & 612 & 2.58 & 140 \\
8 & 30 & 70 & 611 & 3.10 & 167 \\
9 & 20 & 80 & 604 & 4.74 & 176 \\
10 & 10 & 90 & 602 & 6.54 & 212
\end{tabular}

${ }^{a}$ The excitation wavelength was $409 \mathrm{~nm} .{ }^{b}$ Emission quantum yield measured at $298 \mathrm{~K}$ with reference to $\left[\mathrm{Ru}(\mathrm{bpy})_{3}\right]^{2+}, \Phi_{\mathrm{em}}=0.042$ (see ref 28).

substantially blue-shifted (from 666 to $602 \mathrm{~nm}$ ) the corresponding emission maximum. The blue-shift in the emission maximum may be attributed to rigidochromism. ${ }^{27}$ This phenomenon recently was observed for the emission of $\left[\mathrm{Ru}(\mathrm{bpy})_{3}\right]^{2+}$ in many rigid systems. ${ }^{27 a}$ To quantify the emission enhancement in $\mathbf{3}$, the PL quantum yields $\left(\Phi_{\mathrm{em}}\right)$ of $\mathbf{3}$ in acetonitrile-water mixtures were measured, using $\left[\mathrm{Ru}(\mathrm{bpy})_{3}\right]^{2+}$ (bpy $=2,2^{\prime}$-bipyridine) as the reference. ${ }^{28}$ The $\Phi_{\mathrm{em}}$ of the acetonitrile solution of $\mathbf{3}$ was as low as 0.00039 . The $\Phi_{\mathrm{em}}$ rapidly increased with gradual addition of water. When the volume fraction of water in the acetonitrile-water mixture was increased to $90 \%, \Phi_{\mathrm{em}}$ increased to 0.00654 , which was nearly 20 times higher than the $\Phi_{\mathrm{em}}$ of the acetonitrile-only solution (Table 1 ). Similarly, the emission lifetime $\left(\tau_{\mathrm{em}}\right)$ of $\mathbf{3}$ also increased 20 -fold compared to that of $\mathbf{3}$ in acetonitrile.

The trajectory of the change in $\lambda_{\mathrm{em}}, \Phi_{\mathrm{em}}$, and $\tau_{\mathrm{em}}$ suggests that rectangle $\mathbf{3}$ started to aggregate at a water fraction of $>0 \%$ and that the size and population of the aggregates continued to increase as the water fraction increased. Therefore, emission enhancement resulting from fluorescent nanoparticle formation is an alternative way to demonstrate AIE behavior. ${ }^{6}$ Emission enhancement was pronounced only for the 80:20 THF- $\mathrm{H}_{2} \mathrm{O}$ mixture (Supporting Information Figure S2). A possible mechanism for AIE is that aggregation blocks vibrational/torsional energy relaxation, thus populating the radiative state of excitons and enhancing emission. ${ }^{26 a}$ These results suggest that aggregation reduces solvent exposure and distortion of the excited-state environment, i.e., alkyl-chain aggregates expel solvent molecules and aggregation slows vibrational motion. When a poor solvent was added, the molecules of rectangle $\mathbf{3}$ assembled into nanoaggregates, turning the emission "ON" and boosting the PL properties of $\mathbf{3}$. In contrast, in the presence of good solvents, aggregates dispersed into monomers, turning emission "OFF" (Figure 4). Hence, molecular aggregation seems to be the most appropriate explanation for these experimental observations.

Molecular aggregation in solution can be conveniently detected by UV - vis absorption ${ }^{29}$ and fluorescence. ${ }^{30}$ Formation of aggregates commonly is induced by changing the nonsolvent/ solvent volume ratio, as observed for poly ( $p$-phenyleneethynylene) derivatives. ${ }^{29 \mathrm{~b}}$ Clearly, increasing the proportion of nonsolvent in solution makes the solute-solvent interaction less energetically favorable, thereby forcing polymer chain segments to approach each other and form aggregates. Rectangles $\mathbf{1}$ and $\mathbf{2}$ exhibited moderate aggregation, whereas rectangle $\mathbf{3}$ strongly formed nanoaggregates because of the long alkoxy chain. Hence, the spectral properties of $\mathbf{3}$ in the aggregate form were examined. The absorbance of all aggregates at longer wavelengths was due to light scattering of the aggregates, which effectively decreased light transmission through the mixtures (vide infra).

3.4. Light-Scattering Study of 3. Light scattering (LS) is one of the most important techniques used to characterize macromolecules and colloids. Using modern instrumentation, one can readily obtain the average molecular weight and radius of gyration from total intensity (static) light scattering (SLS) and the hydrodynamic (Stokes) radius from dynamic light scattering (DLS). ${ }^{31}$ Thus, light-scattering studies ${ }^{16}$ are useful methods for detecting aggregation.

To prove that $\mathbf{3}$ is an AIE-active molecule, aggregates formed by 3 first were analyzed using the SLS technique. Because these aggregates are kinetically frozen aggregates rather than equilibrium aggregates, the concentration of $\mathbf{3}$ used in the SLS analysis was extremely low. The angular dependence of the SLS data (extrapolated to zero concentration) was investigated (Supporting Information Figure S3). The apparent $M_{\mathrm{w}}$ of the aggregates was determined from the intercept of the straight line with the $y$-axis, as shown in Supporting Information Figure $\mathrm{S} 3$. The average molecular mass of the aggregates of rectangle 3 in $50 \%$ acetonitrile-water mixture was found to be $1.43 \times$ $10^{6}$ from the Zimm plot.

DLS provides information on the dynamic properties of the scattering molecules or aggregates on a microsecond time scale by performing an autocorrelation with the scattering intensity data. To gain insight into the particle size of aggregates, the aggregation of $\operatorname{Re}(\mathrm{I})$-rectangles was monitored using the DLS technique. A typical DLS study of $\operatorname{Re}(\mathrm{I})$-aggregate is shown in Figure 5, where only one mode can be identified. The cumulant and histogram analyses gave diameters of 262 and $265 \mathrm{~nm}$, respectively, for the aggregates of $\operatorname{Re}(\mathrm{I})$-rectangle $\mathbf{3}$, suggesting the formation of uniform aggregates in solution.

3.5. Quenching Studies. To gain a better insight into the excited-state dynamics of the aggregates of alkoxy-bridged Re(I)-rectangle, intermolecular quenching experiments of aggregated $\operatorname{Re}(\mathrm{I})$ species with quinones and aromatic amines were performed. Though it is well-known that intermolecular electron transfer occurs between the lowest excited state of the $\operatorname{Re}(\mathrm{I})-$ polypyridyl complex and quinones/amines, ${ }^{17}$ the emission quenching of aggregated $\operatorname{Re}(\mathrm{I})$ complexes has not yet been reported. Therefore, the quenching experiments were performed by exciting $\operatorname{Re}(\mathrm{I})$-aggregates in the presence of biologically important quinones and amines. The optical density at the excitation wavelength $(390 \mathrm{~nm})$ remained unchanged in the presence of most of quenchers (note that the quencher does not 


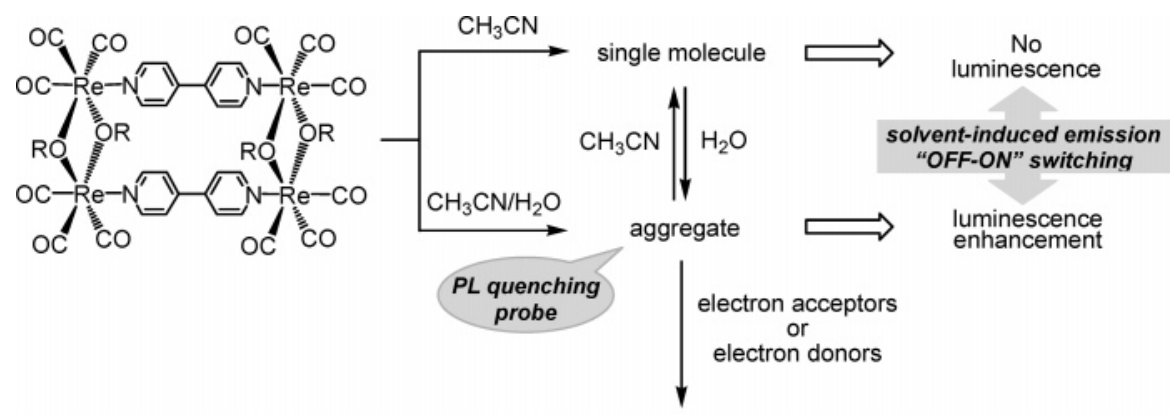

dynamic and static

quenching

Figure 4. Schematic representation of the solvent-induced emission "OFF-ON" switching property of Re(I)-rectangles and of the aggregate of alkoxy-bridged $\operatorname{Re}(\mathrm{I})$-rectangle as a probe for photoluminescence (PL) quenching.

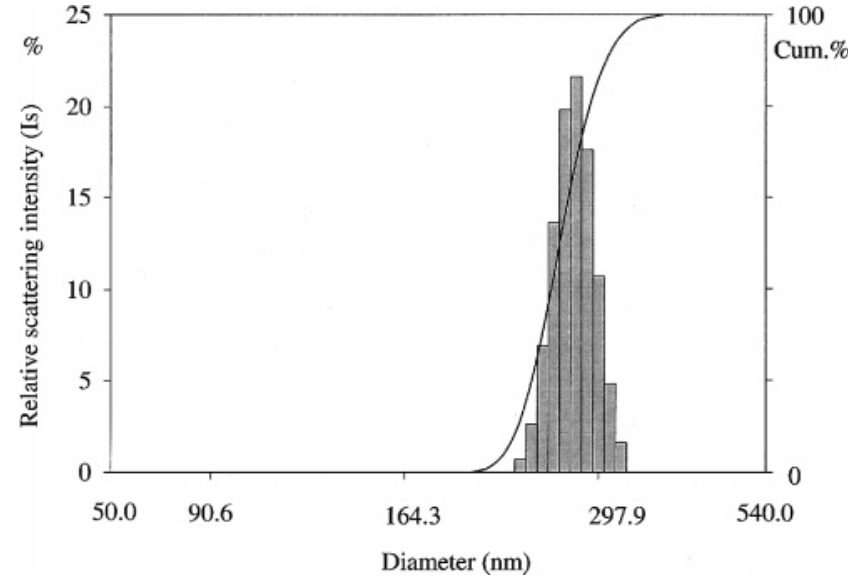

Figure 5. Size distribution of DLS data for the aggregates of $\operatorname{Re}(\mathrm{I})$ rectangle $\mathbf{3}$ in the form of a relative scattering intensity (Is) against diameter.

absorb at this wavelength). This result indicated that the energy transfer from $\operatorname{Re}(\mathrm{I})$-aggregates to quinones or amines was endothermic and the most probable quenching mechanism was electron transfer. Exciplex formation was not observed under the experimental conditions used in the current study. The ratios of fluorescence intensity measured at $612 \mathrm{~nm}$ without and with the quenchers $\left(I_{\mathrm{o}} / I\right)$ were plotted against the quencher concentration [Q]. For pure organic solvents, where the complex existed only as monomers, quenching was not detected. Emission quenching of aggregated $\operatorname{Re}(\mathrm{I})$-rectangle 3 observed at different concentrations of 2,5-dichloro-1,4-benzoquinone and $\mathrm{N}$-ethylaniline is shown in Figures 6 and 7, respectively.

The bimolecular rate constants were estimated from the quenching of $\operatorname{Re}(\mathrm{I})$-aggregates with electron donors and acceptors using the Stern-Volmer eq 6. The plot of $I_{\mathrm{o}} / I$ versus [Q] showed that there was a linear relationship (eq 6) between $I_{\mathrm{o}} / I$ and $[\mathrm{Q}]$ when $[\mathrm{Q}]$ was low.

$$
I_{\mathrm{o}} / I=1+k_{\mathrm{q}} \tau_{\mathrm{o}}[\mathrm{Q}]
$$

where $I_{0}$ is the luminescence intensity of excited $\operatorname{Re}(\mathrm{I})$ aggregates in the absence of quenchers, $I$ is the emission intensity of $* \operatorname{Re}(\mathrm{I})$-aggregates in the presence of quenchers, [Q] is the concentration of the quenchers, and $\tau_{\mathrm{o}}$ is the excitedstate lifetime of $\operatorname{Re}(\mathrm{I})$-aggregates in a $50 \%$ acetonitrile-water mixture $\left(\tau_{\mathrm{o}}=137 \mathrm{~ns}\right)$. The quenching rate constants $\left(k_{\mathrm{q}}\right)$, determined from the slope of the plots, for the two types of quenchers, i.e., quinones (electron acceptors) and amines (electron donors), are summarized in Tables 2 and 3, respectively. While analyzing the quenching rate constants, a gradual increase in the $k_{\mathrm{q}}$ values was noticed with the oxidation/reduction potentials of quinones and amines.

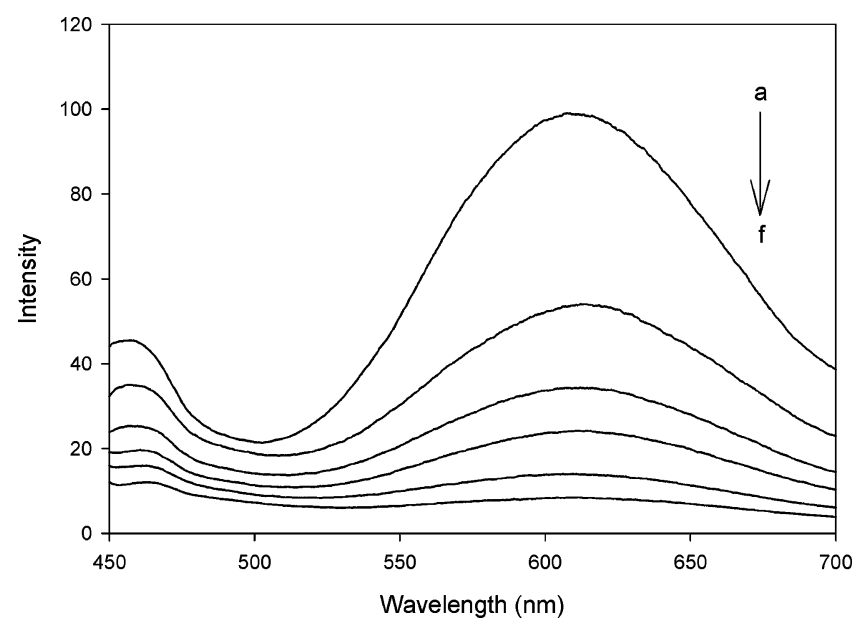

Figure 6. Luminescence quenching of the aggregated form of $\operatorname{Re}(\mathrm{I})$ rectangle 3 with 2,5-dichloro-1,4-benzoquinone: (a) 0 , (b) $4 \times 10^{-3}$, (c) $8 \times 10^{-3}$, (d) $12 \times 10^{-3}$, (e) $16 \times 10^{-3}$, and (f) $20 \times 10^{-3} \mathrm{M}$ quencher in $50 \%$ aqueous acetonitrile at $298 \mathrm{~K}$.

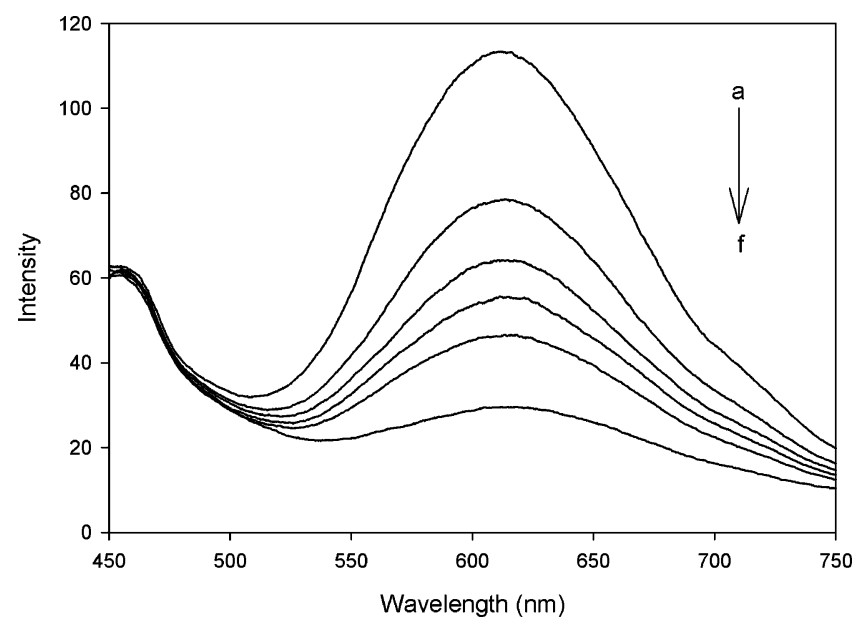

Figure 7. Luminescence quenching of the aggregated form of Re(I)rectangle 3 with $N$-ethylaniline: (a) 0 , (b) $4 \times 10^{-3}$, (c) $8 \times 10^{-3}$, (d) $12 \times 10^{-3}$, (e) $16 \times 10^{-3}$, and (f) $20 \times 10^{-3} \mathrm{M}$ quencher in $50 \%$ aqueous-acetonitrile mixture at $298 \mathrm{~K}$.

More interestingly, the bimolecular quenching rate constants were higher for bulky quenchers than for other quenchers. For example, the triplet excited-state quenching rate constant for $\operatorname{Re}(\mathrm{I})$-aggregates with the electron acceptor, tetracyanoquinodimethane (TCNQ), was found to be 3 orders of magnitude higher than that with benzoquinone. In the case of electron donors, the $k_{\mathrm{q}}$ value of $N, N, N^{\prime}, N^{\prime}$-tetramethylbenzidine also was found to be 3 orders of magnitude higher than the $k_{\mathrm{q}}$ of aniline. In addition to the favorable redox potential, this phenomenon 
TABLE 2: Dynamic and Static Stern-Volmer Constants and Quenching Rate Constants for the Aggregated Form of $\operatorname{Re}(I)$-Rectangle 3 with Electron Acceptors in 50\% Acetonitrile-Water Mixture at 298 K

\begin{tabular}{lccc}
\hline \multicolumn{1}{c}{ quenchers } & $K_{\mathrm{D}}, \mathrm{M}^{-1}$ & $K_{\mathrm{S}}, \mathrm{M}^{-1}$ & $k_{\mathrm{q}}, \mathrm{M}^{-1} \mathrm{~s}^{-1}$ \\
\hline benzoquinone & $2.8 \times 10^{1}$ & $1.4 \times 10^{1}$ & $2.0 \times 10^{8}$ \\
methyl- -benzoquinone & $2.4 \times 10^{3}$ & $4.1 \times 10^{2}$ & $7.6 \times 10^{9}$ \\
2,5-dichloro-1,4-benzoquinone & $2.6 \times 10^{2}$ & $7.6 \times 10^{1}$ & $1.9 \times 10^{9}$ \\
1,4-naphthaquinone & $1.2 \times 10^{2}$ & $1.7 \times 10^{1}$ & $8.9 \times 10^{8}$ \\
1,4-chloranil & $6.2 \times 10^{2}$ & $9.4 \times 10^{1}$ & $4.5 \times 10^{9}$ \\
1,2-chloranil & $1.2 \times 10^{3}$ & $2.1 \times 10^{2}$ & $8.6 \times 10^{9}$ \\
duroquinone & $2.1 \times 10^{2}$ & $8.4 \times 10^{1}$ & $1.5 \times 10^{9}$ \\
tetracyanoquinodimethane (TCNQ) & $5.3 \times 10^{4}$ & $3.2 \times 10^{4}$ & $3.8 \times 10^{11}$
\end{tabular}

TABLE 3: Dynamic and Static Stern-Volmer Constants and Quenching Rate Constants for the Aggregated Form of $\operatorname{Re}(\mathrm{I})$-Rectangle 3 with Electron Donors in $50 \%$ Acetonitrile-Water Mixture at $298 \mathrm{~K}$

\begin{tabular}{llll}
\hline \multicolumn{1}{c}{ quenchers } & $K_{\mathrm{D}}, \mathrm{M}^{-1}$ & $K_{\mathrm{S}}, \mathrm{M}^{-1}$ & $k_{\mathrm{q}}, \mathrm{M}^{-1} \mathrm{~s}^{-1}$ \\
\hline aniline & 1.4 & 0.7 & $1.0 \times 10^{7}$ \\
$N$-methylaniline & $4.1 \times 10^{1}$ & $4.5 \times 10^{1}$ & $3.0 \times 10^{8}$ \\
$N$-ethylaniline & $8.8 \times 10^{1}$ & $3.7 \times 10^{1}$ & $6.4 \times 10^{8}$ \\
$N, N$-dimethylaniline & $8.2 \times 10^{1}$ & $3.9 \times 10^{1}$ & $6.0 \times 10^{8}$ \\
$N, N$-diethylaniline & $3.8 \times 10^{2}$ & $1.3 \times 10^{2}$ & $2.8 \times 10^{9}$ \\
$p$-anisidine & $9.3 \times 10^{1}$ & $1.1 \times 10^{2}$ & $6.8 \times 10^{8}$ \\
$N, N$-dimethyl-p-toluidine & $3.8 \times 10^{2}$ & $8.5 \times 10^{2}$ & $2.8 \times 10^{9}$ \\
diphenylamine & $1.3 \times 10^{3}$ & $1.3 \times 10^{3}$ & $9.2 \times 10^{9}$ \\
$p$-phenylenediamine & 6.0 & 0.9 & $4.4 \times 10^{7}$ \\
$N, N, N^{\prime}$, & $4.0 \times 10^{2}$ & $4.9 \times 10^{2}$ & $2.9 \times 10^{9}$ \\
$N^{\prime}$-tetramethylphenylenediamine & & & \\
benzidine & $2.3 \times 10^{3}$ & $2.2 \times 10^{3}$ & $1.7 \times 10^{10}$ \\
$N, N, N^{\prime}, N^{\prime}$-tetramethylbenzidine & $2.6 \times 10^{3}$ & $1.6 \times 10^{3}$ & $1.9 \times 10^{10}$
\end{tabular}

may be attributed to entrapment of quenchers in the $\operatorname{Re}(\mathrm{I})$ aggregate, possibly due to the hydrophobicity of the quencher. Hence, bulky quenchers may be trapped more efficiently than nonbulky quenchers in the hydrophobic network of $\operatorname{Re}(\mathrm{I})$ aggregates, resulting in higher quenching rate constants. At high quencher concentration, the Stern-Volmer plots for quenching of the $\operatorname{Re}(\mathrm{I})$-aggregates showed curves that deviated upward (Figure 8), indicating that these quenching reactions proceeded through both dynamic and static quenching mechanisms. For ideal cases of quenching, the following Stern-Volmer relationship can be applied (eq 7).

$$
I_{\mathrm{o}} / I=\left(1+K_{\mathrm{D}}[\mathrm{Q}]\right)\left(1+K_{\mathrm{S}}[\mathrm{Q}]\right)
$$

where $K_{\mathrm{D}}$ and $K_{\mathrm{S}}$ are the dynamic and static Stern-Volmer constants, respectively. A nonlinear Stern-Volmer plot suggested the presence of a static component to the quenching mechanism, in addition to dynamic quenching. The bimolecular dynamic quenching rate constants were relatively moderate for all systems, though the measured decrease in fluorescence intensity indicated moderate static fluorescence quenching. The data provide one piece of evidence for the formation of nonfluorescent or weak ground-state complexes between the sensitizer and quenchers. Only within these complexes, that is, upon contact, does efficient fluorescence quenching via electron transfer occur. The quencher activity, as characterized by the Stern-Volmer constant, should be determined, at least in part, by the binding constant (static constant)-even in the case of dynamic quenching, as is known from porphyrin aggregates. ${ }^{32}$ It has been reported that the Stern-Volmer plot deviates from linearity at higher concentrations of electron donors, such as $N, N$-dimethylaniline and $N, N$-diethylaniline. ${ }^{33}$

In addition to ${ }^{1} \mathrm{H}$ NMR and UV-vis spectroscopy, the binding affinities for host molecules also can be measured by emission titration. This method is advantageous because ${ }^{1} \mathrm{H}$ NMR measurements in water on aggregated host molecules are

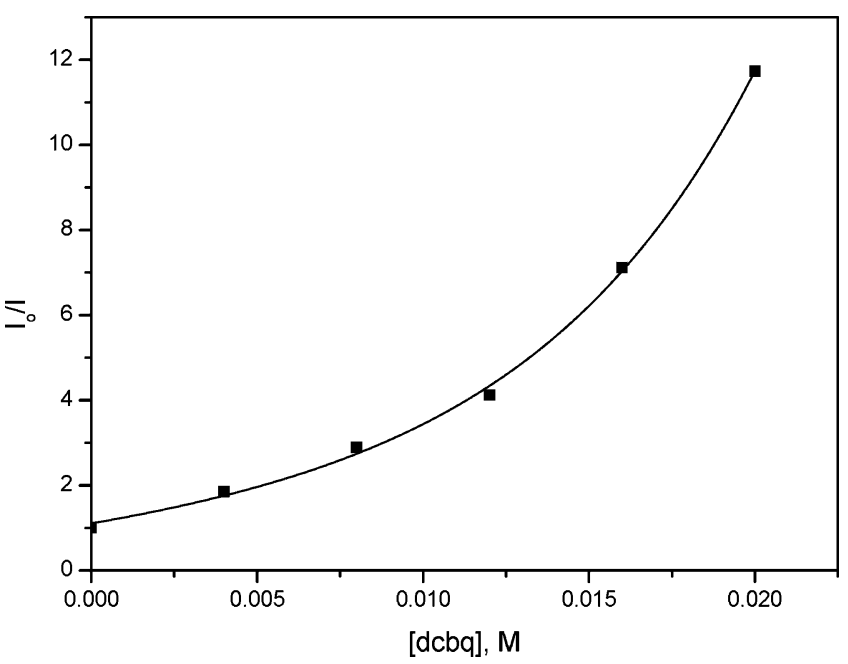

Figure 8. Stern-Volmer plot for the luminescence quenching of the aggregated form of $\operatorname{Re}(\mathrm{I})$-rectangle 3 with 2,5-dichloro-1,4-benzoquinone in $50 \%$ acetonitrile-water mixture at $298 \mathrm{~K}$.

hampered by broadening of the resonance, making accurate binding studies impossible. When guest molecules were added to the $\operatorname{Re}(\mathrm{I})$-aggregates, no appreciable change in the type of aggregates was observed by UV-vis spectroscopy. Hence, neutral host-guest binding studies were followed using the emission titration technique. The luminescence intensity of the excited $\operatorname{Re}(\mathrm{I})$-aggregates decreased when quencher was added. In the case of quinones, the $\operatorname{Re}(\mathrm{I})$-aggregates were the electron donors and the quinones the electron acceptors. When amines were used as the quencher, the $\operatorname{Re}(\mathrm{I})$-aggregates were the electron acceptors, and the amines were the donors. However, in pure acetonitrile, there was no emission quenching between * $\operatorname{Re}(\mathrm{I})$-rectangles and quenchers. In contrast, in aqueous acetonitrile, emission quenching occurred between $* \operatorname{Re}(\mathrm{I})$-aggregates and quenchers due to the increase in proximity resulting from aggregation induced by the hydrophobicity of the $\operatorname{Re}(\mathrm{I})$ and quenchers. From the above experimental results, it was concluded that, under different conditions, excited $\operatorname{Re}(\mathrm{I})$-rectangles serve as electron donors or acceptors. The present study is the first to confirm our preliminary communication describing this phenomenon in $\operatorname{Re}(\mathrm{I})$-based rectangles. ${ }^{20}$

From the view of designing quenchers, those that are hydrophobic and/or electron accepting or withdrawing give rise to more efficient PL quenching. Photoinduced electron transfer from conjugated polymers to electron acceptors, such as TCNQ and its derivatives, has been extensively investigated. ${ }^{34}$ In the present case, the TCNQ may be trapped more efficiently in the hydrophobic network of $\operatorname{Re}(\mathrm{I})$-aggregates, resulting in a higher quenching rate constant. It is interesting to note that TCNQ forms more ground-state complexes compared with other quenchers, since $\operatorname{Re}(\mathrm{I})$ moderately reduces TCNQ in the ground state. ${ }^{35}$ By comparing the $k_{\mathrm{q}}$ value of TCNQ with that of $N, N, N^{\prime}, N^{\prime}$-tetramethylbenzidine, it is apparent that TCNQ is a better quencher of $\operatorname{Re}(\mathrm{I})$-aggregate emission than $N, N, N^{\prime}, N^{\prime}$ tetramethylbenzidine because the quenching process is driven by the hydrophobic effect. On the basis of the measured $k_{\mathrm{q}}$ values, which were much larger than $1 \times 10^{10} \mathrm{M}^{-1} \mathrm{~s}^{-1}$, a diffusional control emission quenching process appears to be very unlikely. ${ }^{36}$ Therefore, the preassociation quenching process induced by hydrophobic-driven aggregation is very similar to the static quenching process. Significant is the fact that $\operatorname{Re}(\mathrm{I})$ rectangles act as surfactants when proper aliphatic chains are introduced. Therefore, one may consider this new class of rectangle to be a "surfactant with a host-guest type recognition 
site." The emission data suggest that the cavity of $\operatorname{Re}(\mathrm{I})$-rectangle is not sufficiently large to accommodate guest molecules. At high guest molecule concentrations, the $\lambda_{\max }{ }^{\mathrm{em}}$ becomes constant at $613 \mathrm{~nm}$, which is exactly the same wavelength as that induced by the aggregation of amphiphilic $\operatorname{Re}(\mathrm{I})$-rectangle in the presence of water. Therefore, guest molecules are expected to bind to the hydrophobic domain consisting of the aliphatic chains of aggregated $\operatorname{Re}(\mathrm{I})$ species.

\section{Conclusion}

In summary, the ON-OFF phenomenon of AIE enhancement in $\operatorname{Re}(\mathrm{I})$ molecular rectangles was achieved by introducing long alkoxy chains as one ligand and changing the solvent from an organic to an aqueous solution. For the first time, the particle size and molecular mass of $\operatorname{Re}(\mathrm{I})$-aggregates were observed using the light-scattering method. Thus, the AIE of the rectangles was attributed to the deactivation of nonradiative decay by restricted intramolecular vibrational and torsional motion. To the best of our knowledge, this is the first example on emission enhancement due to self-aggregation of $\operatorname{Re}(\mathrm{I})$-containing supramolecules. The present study also executes aggregationfacilitated ET between the compound $\mathbf{3}$ and electron donors and acceptors via both static and dynamic quenching processes. Understanding the formation and structure of aggregates-early stages in the formation of solid-state films - will provide valuable guidance in the development of materials with improved luminescence efficiency.

Acknowledgment. We thank Academia Sinica and the National Science Council of Taiwan for financial support.

Supporting Information Available: Crystallographic data in CIF format for 1, figures of UV-vis absorption spectra, emission enhancement, angular dependence of the SLS data, and a Stern-Volmer plot for $\mathbf{3}$. This material is available free of charge via the Internet at http://pubs.acs.org.

\section{References and Notes}

(1) (a) Kalyanasundaram, K. In Photochemistry in Organized and Constrained Media; Ramamurthy, V., Ed.; VCH Publishers: New York, 1991; Chapter 2. (b) Bohne, C.; Redmond, R. W.; Scaiano, J. C. In Photochemistry in Organized and Constrained Media; Ramamurthy, V., Ed.; VCH Publishers: New York, 1991; Chapter 3. (c) Gehlem, M. H.; Schryver, F. C. D. Chem. Rev. 1993, 93, 199. (d) Quina, F. H.; Lissi, E. A. Acc. Chem. Res. 2004, 37, 703

(2) (a) Kalyanasundaram, K. In Photochemistry in Microheterogeneous System; Academic Press: New York, 1987. (b) Margineanu, A.; Hofkens, J.; Cotlet, M.; Habuchi, S.; Stefan, A.; Qu, J.; Kohl, C.; Mullen, K.; Vercammen, J.; Engelborghs, Y.; Gensch, T.; De Schryver, F. C. J. Phys. Chem. B 2004, 108, 12242 .

(3) (a) Wu, J.; Abu-Omar, M. M.; Tolbert, S. H. Nano Lett. 2001, 1 , 27. (b) Kobayashi, K.; Sato, H.; Kishi, S.; Kato, M.; Ishizaka, S.; Kitamura N.; Yamagishi, A. J. Phys. Chem. B 2004, 108, 18665. (c) Chu, B. W. K.; Yam, V. W. W. Inorg. Chem. 2001, 40, 3324. (d) Bowers, J.; Amos, K. E.; Bruce, D. W. Langmuir 2005, 21, 1346.

(4) (a) Fuhrhop, J. H.; Bindig, U.; Siggel, U. J. Am. Chem. Soc. 1993, 115, 11036. (b) Yam, V. W. W.; Li, B.; Yang, Y.; Chu, B. W. K.; Wong, K. M. C.; Cheung, K. K. Eur. J. Inorg. Chem. 2003, 4035. (c) Dag, O.; Soten, I.; Çelik, O.; Polarz, S.; Coombs, N.; Ozin, G. A. Adv. Funct. Mater. 2003, 13, 30 .

(5) (a) Russel, J. C.; Whitten, D. G. J. Am. Chem. Soc. 1981, 103, 3219. (b) Garcia-Ortega, H.; Bourdelande, J. L.; Crusats, J.; El-Hachemi, Z.; Ribo, J. M. J. Phys. Chem. B 2004, 108, 4631. (c) Hsu, Y.-H.; Chiang, W. H.; Chen, C. H.; Chern, C. S.; Chiu, H. C. Macromolecules 2005, 38, 9757.

(6) (a) An, B. K.; Kwon, S. K.; Jung, S. D.; Park, S. Y. J. Am. Chem. Soc. 2002, 124, 14410. (b) Belton, C.; O’Brien, D. F.; Blau, W. J.; Cadby, A. J.; Lane, P. A.; Bradley, D. D. C.; Bryne, H. J.; Stockmann, R.; Horhold,
H. H. Appl. Phys. Lett. 2001, 78, 1059. (c) Jayanty, S.; Radhakrishnan, T. P. Chem.-Eur. J. 2004, 10, 791 .

(7) (a) Antonietti, M.; Goltner, C. Angew. Chem., Int. Ed. Engl. 1997, 36, 911. (b) Nagahara, T.; Imura, K.; Okamoto, H.; Oguro, A.; Imahori, H. J. Phys. Chem. B 2005, 109, 19839. (c) Sun, P.; Jose, D. A.; Shukla, A. D.; Shukla, J. J.; Das, A.; Rathman, J. F.; Ghosh, P. Langmuir 2005, 21, 3413.

(8) Dominguez-Gutierrez, D.; Surtchev, M.; Eiser, E.; Elsevier, C. J. Nano Lett. 2006, 6, 145.

(9) (a) Shinkai, S.; Mori, S.; Koreishi, H.; Tsubaki, T.; Manabe, O. J. Am. Chem. Soc. 1986, 108, 2409. (b) Satheeshkumar, K. S.; Vasu, G.; Vishalakshi, V.; Moni, M. S.; Jayakumar, R. J. Mol. Recognit. 2004, 17, 67. (c) Zadmard, R.; Schrader, T. J. Am. Chem. Soc. 2005, 127, 904.

(10) Fox, M. A.; Chanon, M. Photoinduced Electron Transfer; Elsevier: Amsterdam, 1988; Parts A-D.

(11) (a) Imahori, H.; Yamada, H.; Guldi, D. M.; Endo, Y.; Shimomura, A.; Kundu, S.; Yamada, K.; Okada, T.; Sakata, Y.; Fukuzumi, S. Angew. Chem., Int. Ed. 2002, 41, 2344. (b) Dutta Choudhury, S.; Basu, S. J. Phys. Chem. A 2005, 109, 8113. (c) Lopez-Cornejo, P.; Hernandez, M.; PerezTejeda, P.; Perez, F.; Prado-Gotor, R.; Sanchez, F. J. Phys. Chem. B 2005, 109, 1703.

(12) (a) Liu, Y.; Hua, R.; Sun, H.-B.; Qiu, X. Organometallics 2005 , 24, 2819. (b) Graham, T. W.; Cariou, R. P. Y.; Sanchez-Nieves, J.; Allen, A. E.; Udachin, K. A.; Regragui, R.; Carty, A. J. Organometallics 2005 $24,2023$.

(13) (a) Benkstein, K. D.; Hupp, J. T.; Stern, C. L. Angew. Chem., Int. Ed. 2000, 39, 2891. (b) Benkstein, K. D.; Hupp, J. T.; Stern, C. L. J. Am Chem. Soc. 1998, 120, 12982.

(14) (a) Woessner, S. M.; Helms, J. B.; Shen, Y.; Sullivan, B. P. Inorg. Chem. 1998, 37, 5406. (b) Sun, S. S.; Lees, A. J. Inorg. Chem. 1999, 38, 4181 .

(15) (a) Manimaran, B.; Rajendran, T.; Lu, Y. L.; Lee, G. H.; Peng, S. M.; Lu, K. L. J. Chem. Soc., Dalton Trans. 2001, 515. (b) Rajendran, T.; Manimaran, B.; Lee, F. Y.; Lee, G. H.; Peng, S. M.; Wang, C. M.; Lu, K. L. Inorg. Chem. 2000, 39, 2016.

(16) (a) Reitz, G. A.; Dressick, W. J.; Demas, J. N.; DeGraff, B. A. J. Am. Chem. Soc. 1986, 108, 5344. (b) Reitz, G. A.; Demas, J. N.; DeGraff, B. A.; Stephens, E. M. J. Am. Chem. Soc. 1988, 110, 5051. (c) Zhang, M.; Lu, P.; Wang, X.; He, L.; Xia, H.; Zhang, W.; Yang, B.; Liu, L.; Yang, L.; Yang, M.; Ma, Y.; Feng, J.; Wang, D.; Tamai, N. J. Phys. Chem. B 2004, 108,13185

(17) (a) Splan, K. E.; Keefe, M. H.; Massari, A. M.; Walters, K. A.; Hupp, J. T. Inorg. Chem. 2002, 41, 619. (b) Sun, S. S.; Lees, A. J. Inorg. Chem. 2001, 40, 3154. (c) Guerrero, J.; Piro, O. E.; Wolcan, E.; Feliz, M. R.; Ferraudi, G.; Moya, S. A. Organometallics 2001, 20, 2842. (d) Thanasekaran, P.; Liao, R. T.; Manimaran, B.; Liu, Y. H.; Chou, P. T.; Rajagopal, S.; Lu, K. L. J. Phys. Chem. A 2006, 110, 10683.

(18) (a) Feliz, M. R.; Ferraudi, G. Inorg. Chem. 2004, 43, 1551. (b) Rajendran, T.; Manimaran, B.; Liao, R. T.; Lin, R. J.; Thanasekaran, P.; Lee, G. H.; Peng, S. M.; Liu, Y. H.; Chang, I. J.; Rajagopal, S.; Lu, K. L. Inorg. Chem. 2003, 42, 6388.

(19) (a) Roodt, A.; Sullivan, J. C.; Meisel, D.; Deutsch, E. Inorg. Chem. 1991, 30, 4545. (b) Kirchhoff, J. R.; Heineman, W. R.; Deutsch, E. Inorg. Chem. 1988, 27, 3608 .

(20) Manimaran, B.; Thanasekaran, P.; Rajendran, T.; Lin, R. J.; Chang, I. J.; Lee, G. H.; Peng, S. M.; Rajagopal, S.; Lu, K. L. Inorg. Chem. 2002 $41,5323$.

(21) Mya, K. Y.; Sirivat, A.; Jamieson, A. M. Macromolecules 2001 , 34,5260 .

(22) Zimm, B. J. Chem. Phys. 1948, 16, 1099.

(23) Sheldrick, G. M. SHELX-97 (including SHELXS and SHELXL); University of Göttingen: Göttingen, Germany, 1997.

(24) Wang, Z.; Shao, H.; Ye, J.; Tang, L.; Lu, P. J. Phys. Chem. B 2005, 109, 19627 .

(25) Tang, B. Z.; Geng, Y.; Lam, J. W. Y.; Li, B.; Jing, X.; Wang, X.; Wang, F.; Pakhomov, A.; Zhang, X. X. Chem. Mater. 1999, 11, 1581.

(26) (a) Chen, J.; Law, C. C. W.; Lam, J. W. Y.; Dong, Y.; Lo, S. M. F.; Williams, I. D.; Zhu, D.; Tang, B. Z. Chem. Mater. 2003, 15, 1535. (b) Luo, J.; Xie, Z.; Lam, J. W. Y.; Cheng, L.; Chen, H.; Qiu, C.; Kwok, H. S.; Zhan, X.; Liu, Y.; Zhu, D.; Tang, B. Z. Chem. Commun. 2001, 1740 (c) Sun, Q.; Lam, J. W. Y.; Xu, K.; Xu, H.; Cha, J. A. P.; Wong, P. C. L.; Wen, G.; Zhang, X.; Jing, X.; Wang, F.; Tang, B. Z. Chem. Mater. 2000, 12, 2617. (d) Tang, B. Z.; Xu, H.; Lam, J. W. Y.; Lee, P. P. S.; Xu, K.; Sun, Q.; Cheuk, K. K. L. Chem. Mater. 2000, 12, 1446.

(27) (a) Glomm, W. R.; Volden, S.; Sjöblom, J.; Lindgren, M. Chem Mater. 2005, 17, 5512. (b) Tran, D.; Bourassa, J. L.; Ford, P. C. Inorg. Chem. 1997, 36, 439.

(28) Rillema, D. P.; Allen, G.; Meyer, T. J.; Conrad, D. Inorg. Chem. 1983, 22, 1617.

(29) (a) Rughooputh, S. D. D. V.; Hotta, S.; Heeger, A. J.; Wudl, F. J. Polym. Sci., Part B: Polym. Phys. 1987, 25, 1071. (b) Halkyard, C. E.; Rampey, M. E.; Kloppenburg, L.; Studer-Martinez, S. L.; Bunz, U. H. F. Macromolecules 1998, 31, 8655. 
(30) Collison, C. J.; Rothberg, L. J.; Treemaneekarn, V.; Li, Y. Macromolecules 2001, 34, 2346.

(31) Burchard, W. In Laser Light Scattering in Biochemistry; Harding, S. E., Sattelle, D. B., Bloomfield, V. A., Eds.; Royal Society of Chemistry: Cambridge, 1992; pp 3-22.

(32) Komatsu, T.; Yanagimoto, T.; Tsuchida, E.; Siggel, U.; Fuhrhop, J. H. J. Phys. Chem. B 1998, 102, 6759.

(33) (a) Sun, Y. P.; Bunker, C. E.; Ma, B. J. Am. Chem. Soc. 1994, 116, 9692. (b) Arbogast, J. W.; Foote, C. S.; Kao, M. J. Am. Chem. Soc.
1992, 114, 2277. (c) Seshadri, R.; Rao, C. N. R.; Pal, H.; Mukherjee, T.; Mittal, J. P. Chem. Phys. Lett. 1993, 205, 395.

(34) (a) Li, F.; Werner, A.; Pfeiffer, M.; Leo, K.; Liu, X. J. Phys. Chem. $B$ 2004, 108, 17076. (b) Jensen, H.; Fermin, D. J.; Moser, J. E.; Girault, H. H. J. Phys. Chem. B 2002, 106, 10908.

(35) Leirer, M.; Knor, G.; Vogler, A. Inorg. Chem. Commun. 1999, 2 , 110.

(36) Shi, J. L.; Chen, X.; Jiang, X. K. J. Org. Chem. 1996, 61, 4698. 